\title{
A New Approach for Identification of Potential Rockfall Source Areas Controlled by Rock Mass Strength at a Regional Scale
}

\author{
Xueliang Wang $1,2,3, * \mathbb{D}$, Haiyang Liu ${ }^{1,2,3}$ and Juanjuan Sun ${ }^{1,2,3} \mathbb{D}$ \\ 1 Key Laboratory of Shale Gas and Geoengineering, Institute of Geology and Geophysics, Chinese Academy of \\ Sciences, Beijing 100029, China; liuhaiyang@mail.iggcas.ac.cn (H.L.); sunjuanjuan17@mails.ucas.edu.cn (J.S.) \\ 2 Innovation Academy for Earth Sciences, Chinese Academy of Sciences, Beijing 100029, China \\ 3 University of Chinese Academy of Sciences, Beijing 100049, China \\ * Correspondence: wangxueliang@mail.iggcas.ac.cn
}

Citation: Wang, X.; Liu, H.; Sun, J. A New Approach for Identification of Potential Rockfall Source Areas Controlled by Rock Mass Strength at a Regional Scale. Remote Sens. 2021, 13, 938. https://doi.org/10.3390/ rs13050938

Academic Editor: Paolo Mazzanti

Received: 7 February 2021

Accepted: 26 February 2021

Published: 3 March 2021

Publisher's Note: MDPI stays neutral with regard to jurisdictional claims in published maps and institutional affiliations.

Copyright: (C) 2021 by the authors. Licensee MDPI, Basel, Switzerland. This article is an open access article distributed under the terms and conditions of the Creative Commons Attribution (CC BY) license (https:// creativecommons.org/licenses/by/ $4.0 /)$.

\begin{abstract}
The identification of rockfall source areas is a fundamental work for rockfall disaster prevention and mitigation. Based on the Culmann model, a pair of important indicators to estimate the state of slope stability is the relief and slope angles. Considering the limit of field survey and the increasing requirements for identification over a large area, a new approach using the relief-slope angle relationship to identify rockfall source areas controlled by rock mass strength at a regional scale is proposed in this paper. Using data from helicopter-based remote sensing imagery, a digital elevation model of $10 \mathrm{~m}$ resolution, and field work, historical rockfalls in the Wolong study area of Tibet where frequent rockfalls occur are identified. A clear inverse relationship between the relief and slope angles of historical rockfalls enables us to calculate the rock mass strength of the landscape scale by the Culmann model and the relief-slope angle relationship curve. Other parameters used in our proposed approach are calculated by ArcGIS and statistic tools. By applying our approach, the potential rockfall source areas in the study are identified and further zoned into three susceptibility classes that could be used as a reference for a regional rockfall susceptibility study. Using the space partition of historical rockfall inventory, our prediction result is validated. Most of the rockfall source areas (i.e., $71.92 \%$ ) identified in the validation area are occupied by historical rockfalls, which proves the good prediction of our approach. The dominant uncertainty in this paper is derived from the process of calculating rock mass strength, defining the specific area for searching potential rockfall source areas, and the resolution of the digital elevation model.
\end{abstract}

Keywords: rockfall source areas; identification; relief; slope angle; rock mass strength; rockfall susceptibility

\section{Introduction}

The identification of potential rockfall source areas is the first step in assessing rockfall susceptibility, hazard, risk, and determining rockfall disaster prevention and mitigation [1-7]. However, it is very difficult work to carry out in mountain areas, especially the steep and high-relief slopes, which are not accessible on site. Field investigation provides the most effective method to survey the distribution of potential rockfall source areas at a specific site [8]. Through field investigation, the engineering geology conditions controlling rockfall distribution, including the rock mass strength, orientation of structures, joint density, slope angle, relief, and the activity of tectonic faults, could be carefully studied on site $[7,9,10]$. Recent technologies, including unmanned aerial vehicles, terrestrial laser scanning, monitoring systems, photogrammetry, and point cloud analysis software tools (e.g., AgiSoft, Photoscan, and Coltop) [11-14], help researchers to acquire detailed information of the above conditions.

For the identification of potential rockfall source areas at a regional scale, the traditional field investigation is not as effective as that at a specific site because of its limited investigation scope and because it consumes much time and human resources. Hence, 
some researchers have developed regional rockfall susceptibility models based on ArcGIS to estimate the spatial distribution of rockfall using the causal factors of rockfall including lithology, terrain, elevation, faults, rainfall, and earthquakes [15-17]. Based on the results of rockfall susceptibility assessments, the whole area could be zoned into different areas with different susceptible degrees, which provides useful guidance for regional land use and rockfall disaster prevention plans. Alternatively, some researchers have identified rockfall sources at a regional scale by remote sensing interpretation technologies using multi-temporal aerial photos, helicopter-based remote sensing imagery, and high-resolution digital elevation model (DEM) $[5,6,18]$. Subsequently, regional locations of rockfall source areas could be identified for further rockfall kinematic modeling and predicting regional rockfall hazards [19].

Rock mass strength is thought to be the basic controlling factor of slope stability $[20,21]$. A rock slope with a low rock mass strength fractured by different types of fractures is prone to rockfall [7,22]. Based on Culmann's two-dimensional slope stability model [23], a hillslope is susceptible to rockfall if its relief, slope angle, or both are larger than the threshold values [24-27]. This means that the relief and slope angles are a pair of important indicators that could be used to identify rockfall source areas on the slopes whose stability is dominantly controlled by the rock mass strength. Until now, previous studies rarely focused on the approaches combining the relief and slope angles to identify rockfall source areas controlled by the rock mass strength at a regional scale $[5,28]$. Focusing on this issue, comprehensive technologies, including helicopter-based remote sensing imagery, a DEM with $10 \mathrm{~m}$ resolution, images from Google Earth, and field work, were adopted in this study. Lastly, a new approach, the procedures, and the application criteria for identifying rockfall source areas at a regional scale are proposed and were applied in the study area.

\section{Materials and Methods}

The Wolong (WL) area of Tibet where ideal geological conditions exist to investigate the characteristics of rock mass outcrops and the distribution of rockfall source areas was selected for this study (Figure 1). To identify potential rockfall source areas at a regional scale, a new approach combining the relief and slope angles based on the rock mass strength is proposed.

\subsection{Study Area}

The lithology of the area is mainly diorite and granite with a small component of gneiss $[29,30]$. Because of the steep terrain and the widely distributed tectonic structures, the main type of slope failure in the WL area is rockfall. Based on the rockfall scars left on the steep slopes and the rockfall deposits distributed widely, rockfalls in the study area occur frequently, and the dominant kinematic failure modes are toppling and planer sliding (Figure 2).

In this study, based on a power grid project, the helicopter-based remote sensing imagery obtained in 2017 and the $10 \mathrm{~m}$ resolution DEM over the study area were acquired with the help of the research group State Grid Corporation of China. Using the data of the complete study area, images of Google Earth, and field work, a rockfall inventory including 235 rockfall scars on bedrocks and 109 rockfall deposits was prepared (Figure 1). The rockfall scars were identified based on the fresh bedrock color left on the scars (Figure 2). Because many of the rockfall deposits were removed by the Yarlung Tsangpo River, and some of the rockfalls are adjacent, it was not possible to track each rockfall's deposits. Rockfall deposits at the foot of the slopes were identified based on the shape of the deposit (e.g., pyramid) and the identifiable rockfall blocks (e.g., meters) left on the deposits.

\subsection{Framework of Identifying Potential Rockfall Source Areas}

By using ArcGIS and statistic tools, our new approach proposed in this paper includes the framework as follows: 

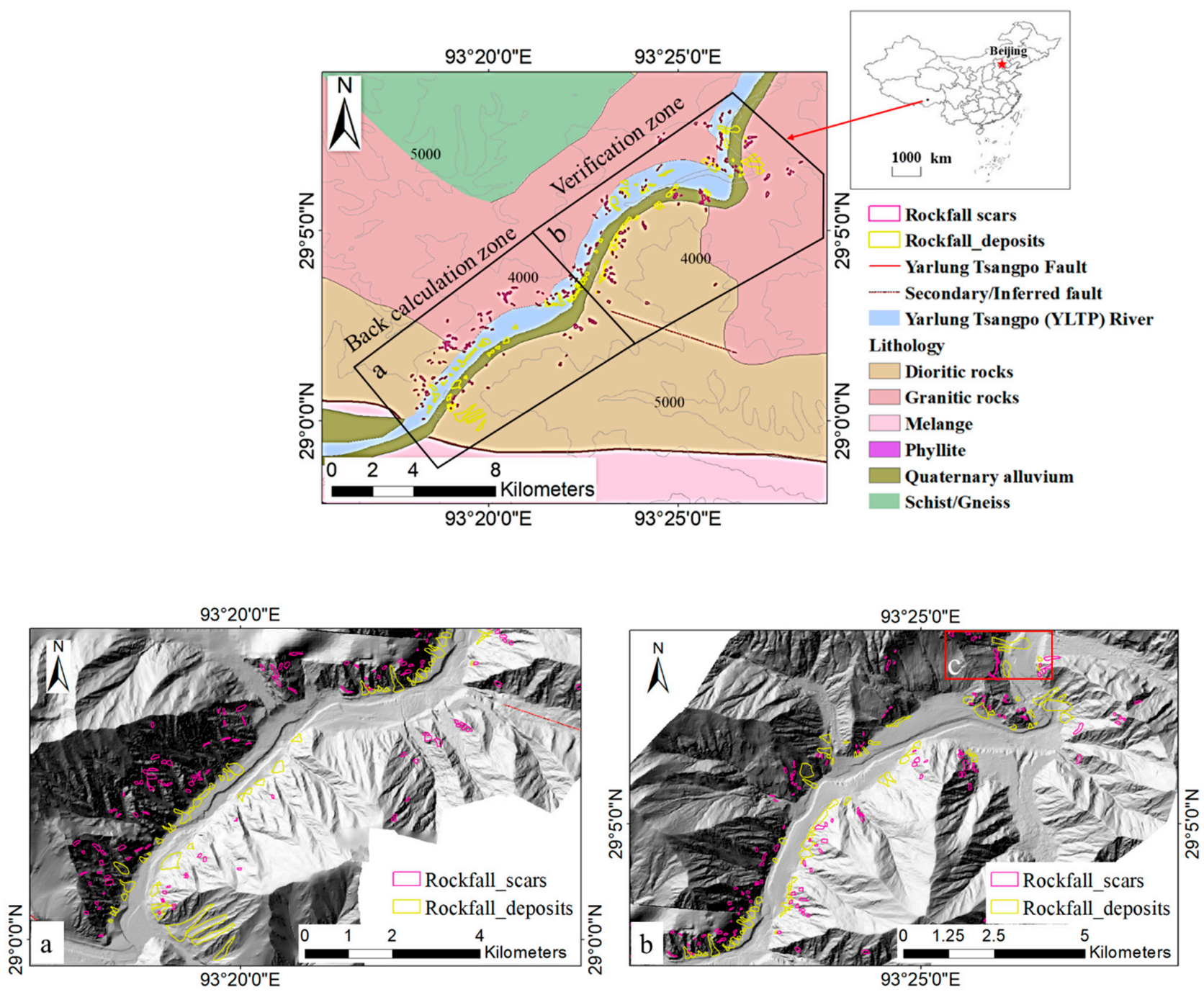

Figure 1. Simplified geology map of the study area. Two zones are separated by the space partition for validation of the prediction result, with (a) the back calculation zone and (b) the verification zone. (c) Sample area presented in Figure 2.

(1) Calculate the rock mass strength parameters $\left(c_{1}, \varphi_{1}\right)$ of the bedrock slope at the landscape scale and build the relief-slope ( $R-S)$ angle relationship curve in the study area (Figure 3a).

(2) Measure the present relief $(H)$ and slope angle $(\beta)$ of each specific area $(A)$ (Figure $3 b$ ) with the potential rockfall over the slope areas.

(3) Calculate the limit relief $\left(H_{c}\right)$ of the specific area $(A)$ by the Culmann model [23] (Figure 3a). The Culmann model indicates that the relief of the slope is controlled by the rock mass strength, and the slope angle $(\beta)$ has the following relationship with the limit relief (maximum height) $\left(H_{c}\right)$ :

$$
H_{c}=\frac{4 C}{\gamma} \frac{\sin \beta \cos \varphi}{[1-\cos (\beta-\varphi)]}
$$

where $c$ is cohesion, $\gamma$ is the bulk density, and $\varphi$ is the internal friction angle.

(4) Compare the present relief $(\mathrm{H})$ and the limit relief $\left(H_{c}\right)$ of the specific area to estimate its state of stability. When the present relief of the bedrock is larger than the limit relief (Figure 3b), the bedrock is prone to generate rockfalls. Hence, the area whose relief exceeds its limit relief is identified as the potential rockfall source area. 
(5) Using the procedure from steps (1) to (4), all areas of the slopes over the study area are searched, and their states of stability are estimated. Eventually, all the potential rockfall source are identified.
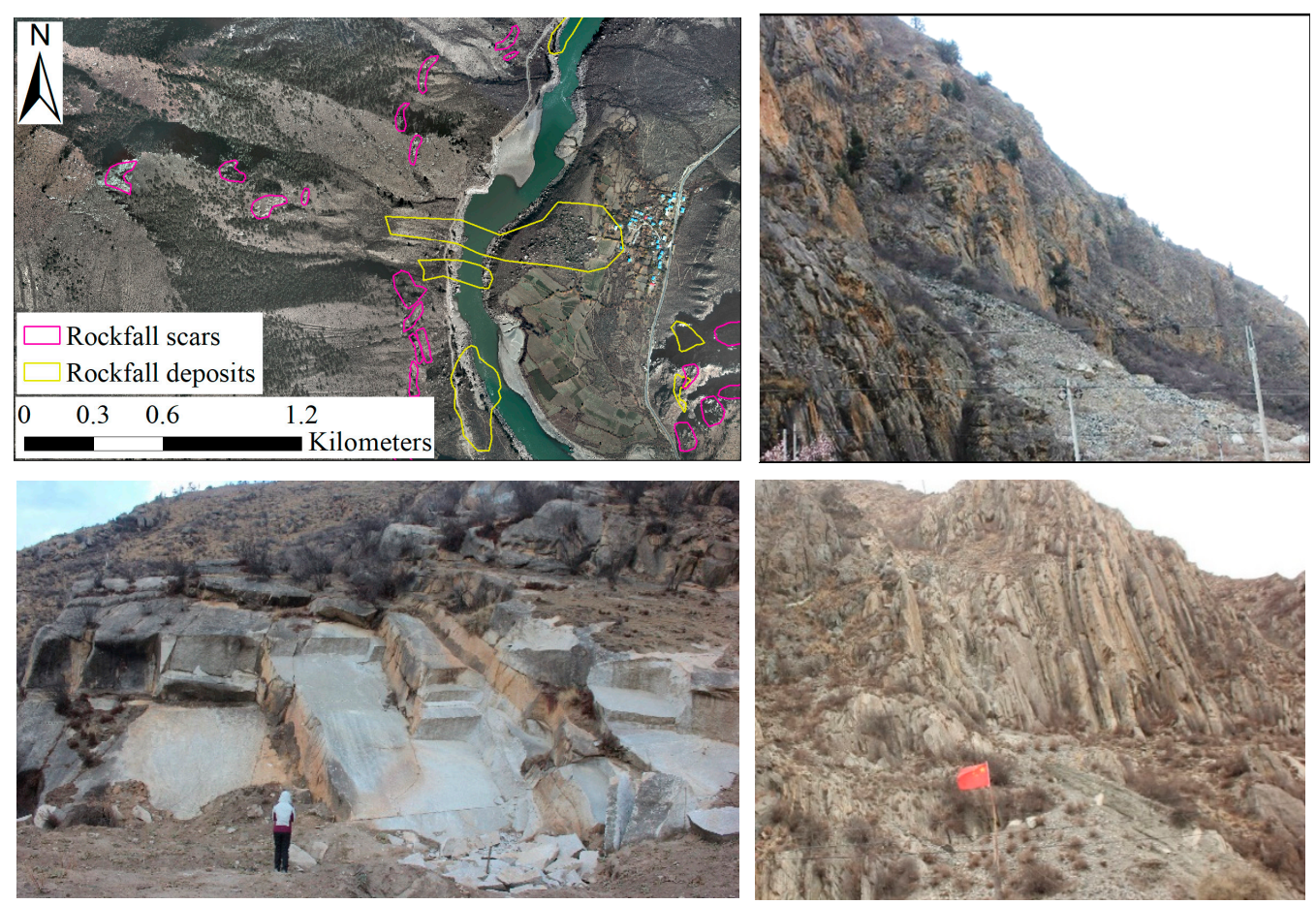

Figure 2. Samples of the rockfall scars and deposits on the helicopter-based remote sensing imagery with the location $\mathrm{c}$ in Figure $1 \mathrm{~b}$ and the historical rockfalls with kinematic failure modes of toppling and planer sliding and their deposits at the foot of the slopes.
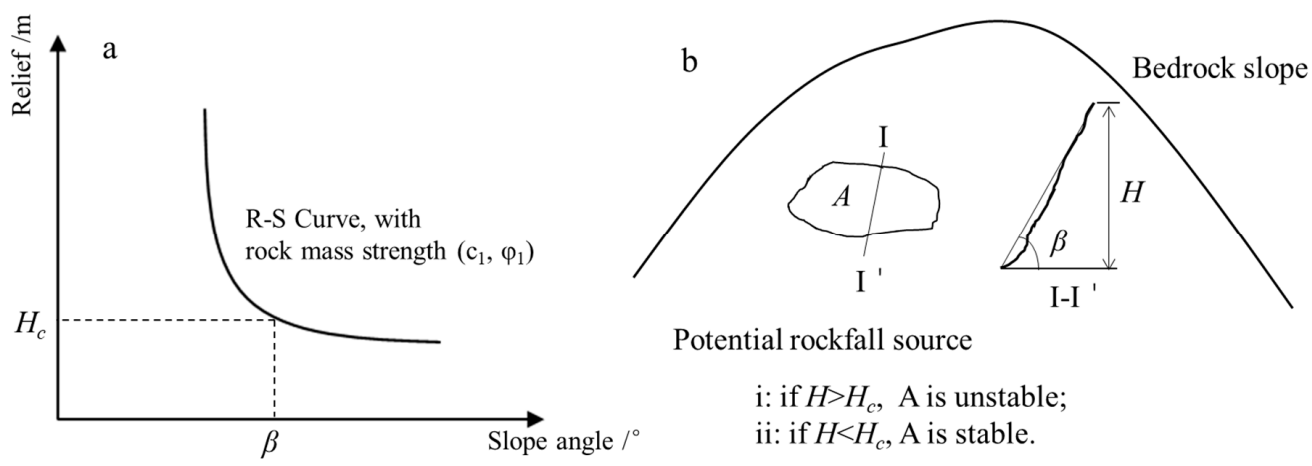

Figure 3. Sketch map describing the approach. (a) Slope angle versus relief for hillslope. (b) Sketch map of estimating the state of stability for the specific area (A).

Different from the availability of rock mass strength tested in the laboratory, the rock mass strength of bedrocks at the landscape scale is very difficult to test on site because of the lack of suitable approaches [20,21]. Schmidt and Montgomery [24] proposed an approach to estimate the rock mass strength parameters $(c, \varphi)$ using the relief and slope angles of historical rockfalls with the Culmann model. Previous studies have applied the approach to calculate the parameters of rock mass strength using the relief and slope angles of historical landsides or rockfall scars in some cases [25-27,31]. In reference to previous studies, data of the relief and slope angles of 235 historical rockfall scars were first extracted by ArcGIS. Then, the parameters of the rock mass strength $(c, \varphi)$ at the landscape scale in our study area were calculated under the precondition that the bedrock relief is controlled by the rock mass strength. 


\section{Results}

The geometrical characteristics of historical rockfalls were analyzed to define the specific area (A) used in the new approach for searching rockfall source areas. Applying our proposed approach, the rockfall source areas were identified in the study area and were zoned into three susceptibility classes.

\subsection{Geometrical Characteristics of Historical Rockfalls}

Before calculating the relief and slope angles of each specific area, a suitable value of the specific area (A) should be first determined. To define the value of A in this study, the geometrical characteristics of 235 historical rockfalls were first analyzed by ArcGIS. The values of the relief and slope angles and the areas of historical rockfalls were measured separately. According to the statistical results, the relief of historical rockfalls is mainly distributed between 40 and $130 \mathrm{~m}$, the slope angle is generally larger than $45^{\circ}$, and the area of each historical rockfall scar is generally less than $9000 \mathrm{~m}^{2}$. All three groups of data show Gaussian distribution characteristics (Figure 4). The mean area of historical rockfalls is $5217 \mathrm{~m}^{2}$, which was adopted as the specific area (A) for searching rockfall source areas of the slopes over the study area.

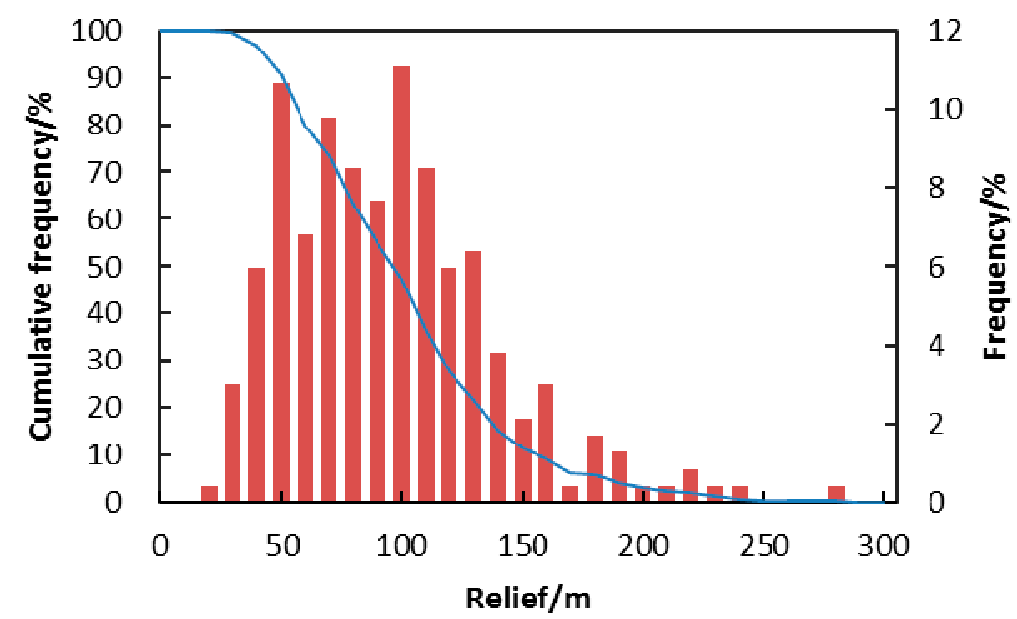

(a). Relief frequency statistics

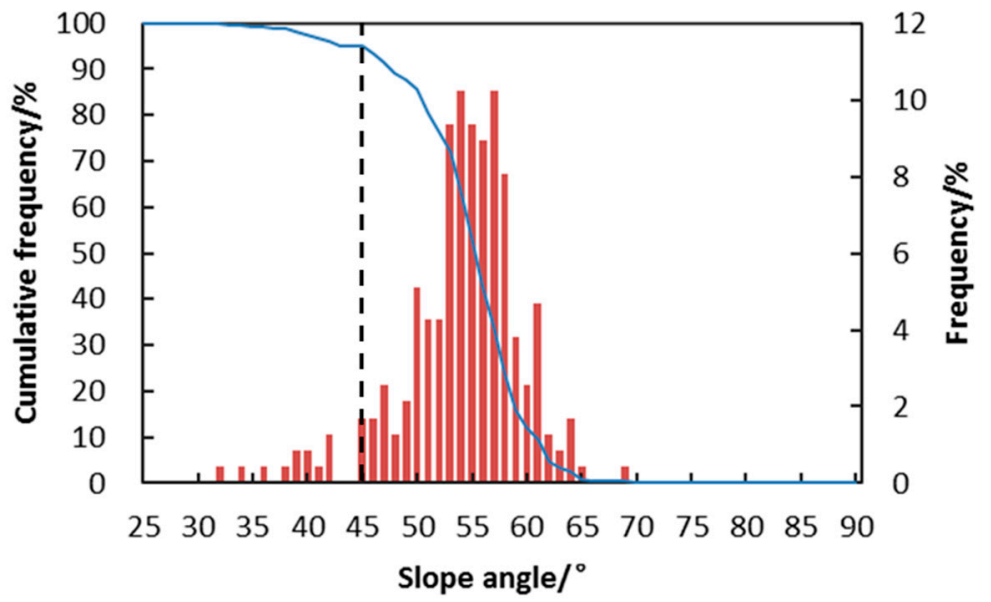

(b). Slope angle frequency statistics

Figure 4. Cont. 


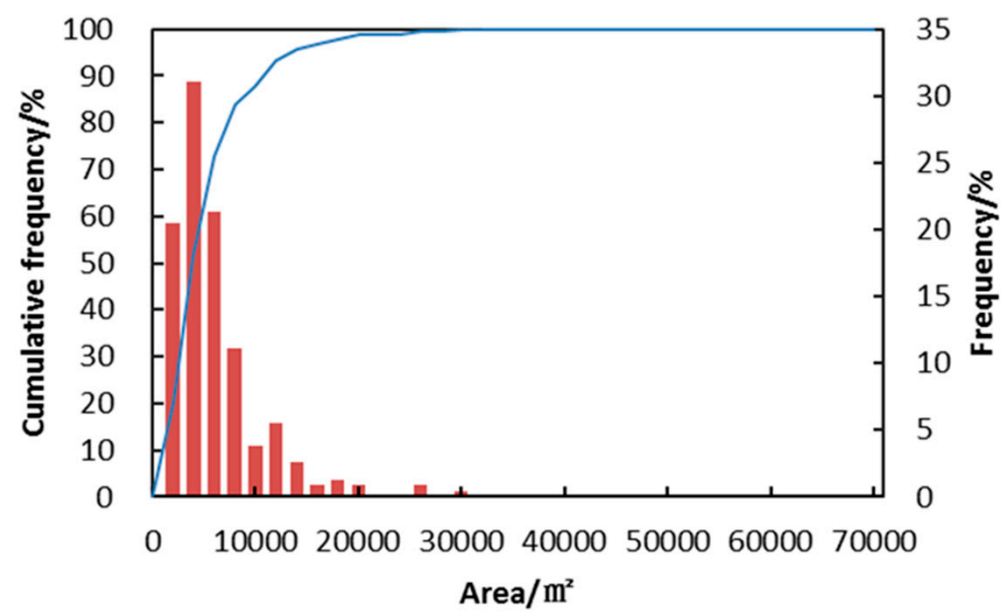

(c). Area frequency statistics

Figure 4. The geometrical statistics of historical rockfalls.

\subsection{Locations of Identified Rockfall Sources}

A clear inverse relationship between the relief and slope angles of 235 historical rockfalls (Figure 5) enabled us to calculate the rock mass strength at the landscape scale in this study. According to previous studies [25-27,31], the minimum and maximum parameters of rock mass strength can be estimated using the lower envelope and the upper envelope of the R-S curves obtained by data of the relief and slope angles of failed slopes. The upper envelope of the R-S curve (Figure 5) represents the maximum strength of the rock mass, and the lower envelope represents the minimum.

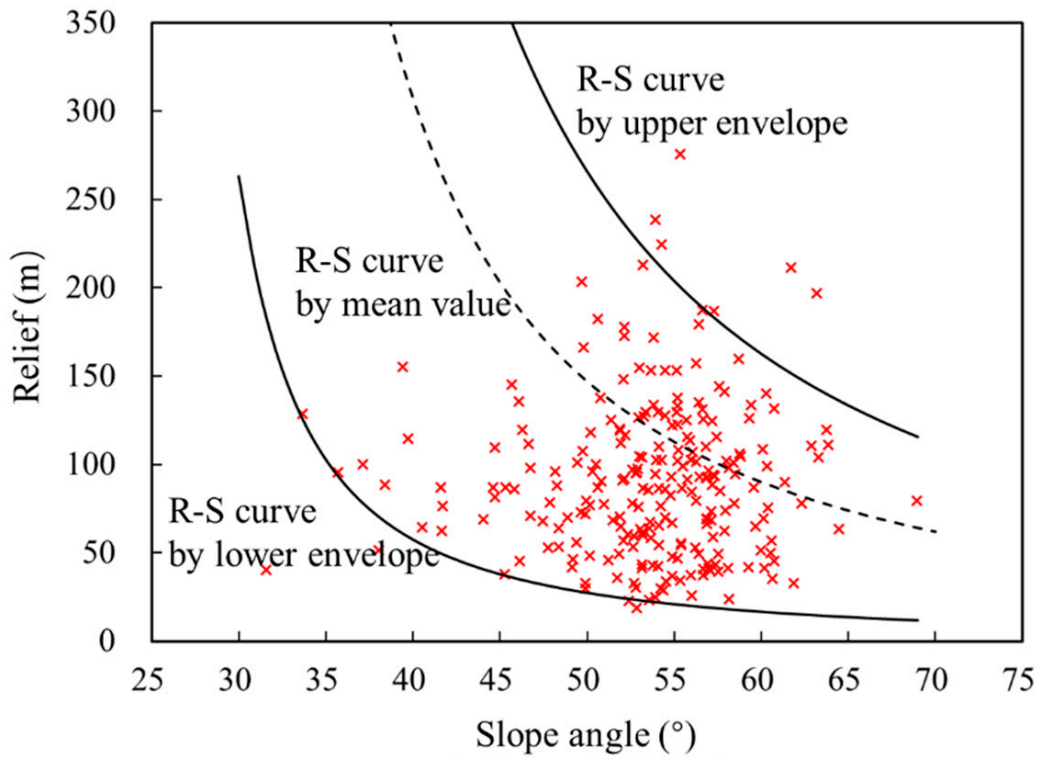

Figure 5. Rock mass strength fitting result and the relief-slope (R-S) angle relationship in the study area.

Applying the results of 235 historical rockfalls to Equation (1) by the optimization algorithm (Figure 5), the minimum and maximum rock mass cohesions $(c)$ in the study area are $28 \mathrm{~Pa}$ and $270 \mathrm{kPa}$, respectively, and both internal friction angles $(\varphi)$ are $23^{\circ}$. Using the upper envelope and the mean value of the upper envelope and the lower envelope, with the lower envelope corresponding to each slope angle, three R-S relationship curves were built as the threshold to determine if each specific area is stable or unstable (Figure 5). 
The R-S curves could be regarded as three different estimates: the aggressive estimate, the moderate estimate, and the conservative estimate, corresponding to the upper envelope, the mean value, and the lower envelope curves, which could be selected by different aims or rockfall disaster prevention and mitigation strategies.

Based on our approach, to identify the rockfall source area is to identify the area whose present relief exceeds the limit relief corresponding to its slope angle (Figure 3). Hence, we calculated the limit relief corresponding to each slope angle (Table 1) using the three R-S curves presented in Figure 5. Considering the actual slope distribution of the historical rockfalls (Figure $4 \mathrm{~b}$ ), we mainly focused on the slopes with angles larger than $45^{\circ}$. Comparing the present relief and the limit relief in each specific area of the slopes in the study area, we obtained the rockfall source areas in ArcGIS (Figure 6). More rockfall source areas are distributed at the lower parts of the slopes whose slope angles are relatively bigger, which is probably affected by the intense incision of the Yarlung Tsangpo River [32].

Table 1. Limit relief of the specific areas corresponding to the slope angle.

\begin{tabular}{|c|c|c|c|c|c|c|c|c|c|c|c|}
\hline \multirow{2}{*}{$\begin{array}{c}\text { Slope } \\
\left.\text { Angle ( }{ }^{\circ}\right)\end{array}$} & \multicolumn{3}{|c|}{ Limit Relief (m) } & \multirow{2}{*}{$\begin{array}{c}\text { Slope } \\
\text { Angle }\left({ }^{\circ}\right)\end{array}$} & \multicolumn{3}{|c|}{ Limit Relief (m) } & \multirow{2}{*}{$\begin{array}{c}\text { Slope } \\
\left.\text { Angle ( }{ }^{\circ}\right)\end{array}$} & \multicolumn{3}{|c|}{ Limit Relief (m) } \\
\hline & C-U & C-M & C-L & & C-U & C-M & C-L & & C-U & C-M & C-L \\
\hline 46.0 & 35.5 & 189.1 & 342.7 & 61.0 & 16.2 & 86.2 & 156.2 & 76.0 & 9.6 & 50.9 & 92.3 \\
\hline 47.0 & 33.2 & 176.7 & 320.3 & 62.0 & 15.6 & 82.8 & 150.0 & 77.0 & 9.3 & 49.4 & 89.5 \\
\hline 48.0 & 31.2 & 165.8 & 300.4 & 63.0 & 15.0 & 79.6 & 144.2 & 78.0 & 9.0 & 47.9 & 86.9 \\
\hline 49.0 & 29.3 & 155.8 & 282.4 & 64.0 & 14.4 & 76.6 & 138.8 & 79.0 & 8.7 & 46.5 & 84.3 \\
\hline 50.0 & 27.6 & 146.9 & 266.1 & 65.0 & 13.9 & 73.7 & 133.6 & 80.0 & 8.5 & 45.2 & 81.9 \\
\hline 51.0 & 26.1 & 138.7 & 251.4 & 66.0 & 13.4 & 71.1 & 128.8 & 81.0 & 8.3 & 43.9 & 79.6 \\
\hline 52.0 & 24.7 & 131.3 & 238.0 & 67.0 & 12.9 & 68.5 & 124.2 & 82.0 & 8.0 & 42.7 & 77.3 \\
\hline 53.0 & 23.4 & 124.6 & 225.7 & 68.0 & 12.4 & 66.2 & 119.9 & 83.0 & 7.8 & 41.5 & 75.2 \\
\hline 54.0 & 22.2 & 118.4 & 214.5 & 69.0 & 12.0 & 63.9 & 115.8 & 84.0 & 7.6 & 40.3 & 73.1 \\
\hline 55.0 & 21.2 & 112.7 & 204.1 & 70.0 & 11.6 & 61.8 & 111.9 & 85.0 & 7.4 & 39.2 & 71.1 \\
\hline 56.0 & 20.2 & 107.4 & 194.6 & 71.0 & 11.2 & 59.7 & 108.2 & 86.0 & 7.2 & 38.2 & 69.2 \\
\hline 57.0 & 19.3 & 102.5 & 185.8 & 72.0 & 10.9 & 57.8 & 104.7 & 87.0 & 7.0 & 37.2 & 67.3 \\
\hline 58.0 & 18.4 & 98.0 & 177.6 & 73.0 & 10.5 & 55.9 & 101.4 & 88.0 & 6.8 & 36.2 & 65.5 \\
\hline 59.0 & 17.6 & 93.8 & 170.0 & 74.0 & 10.2 & 54.2 & 98.2 & 89.0 & 6.6 & 35.2 & 63.8 \\
\hline 60.0 & 16.9 & 89.9 & 162.9 & 75.0 & 9.9 & 52.5 & 95.2 & 90.0 & 6.5 & 34.3 & 62.2 \\
\hline
\end{tabular}

Note: for the slope angle, the front part is open interval, and latter part is closed interval. For example, 46 represents the range of $(45,46]$. C-U: R-S curve by upper envelope; C-M: R-S curve by mean value; C-L: R-S curve by lower envelope.

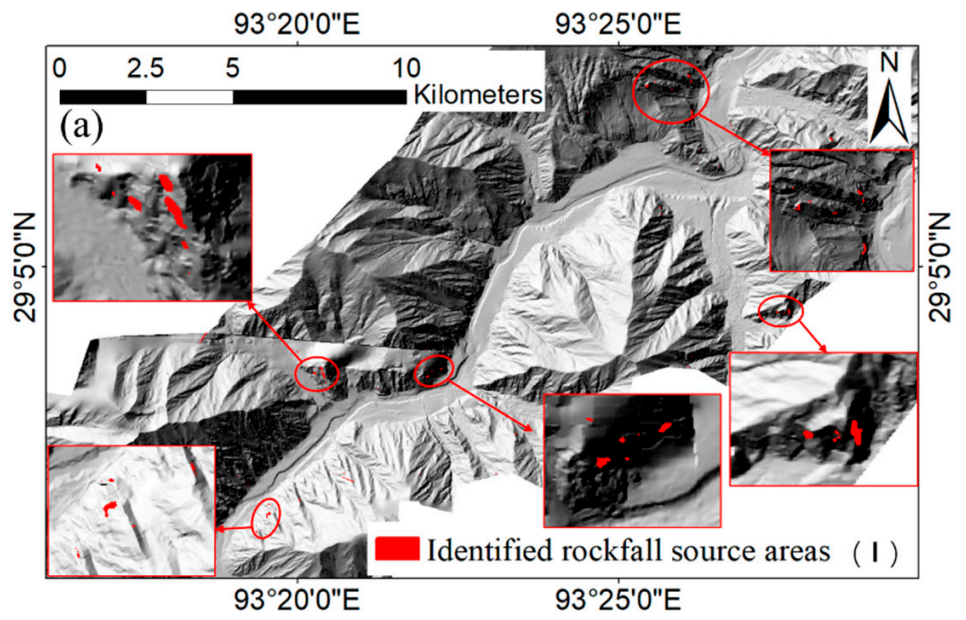

Figure 6. Cont. 


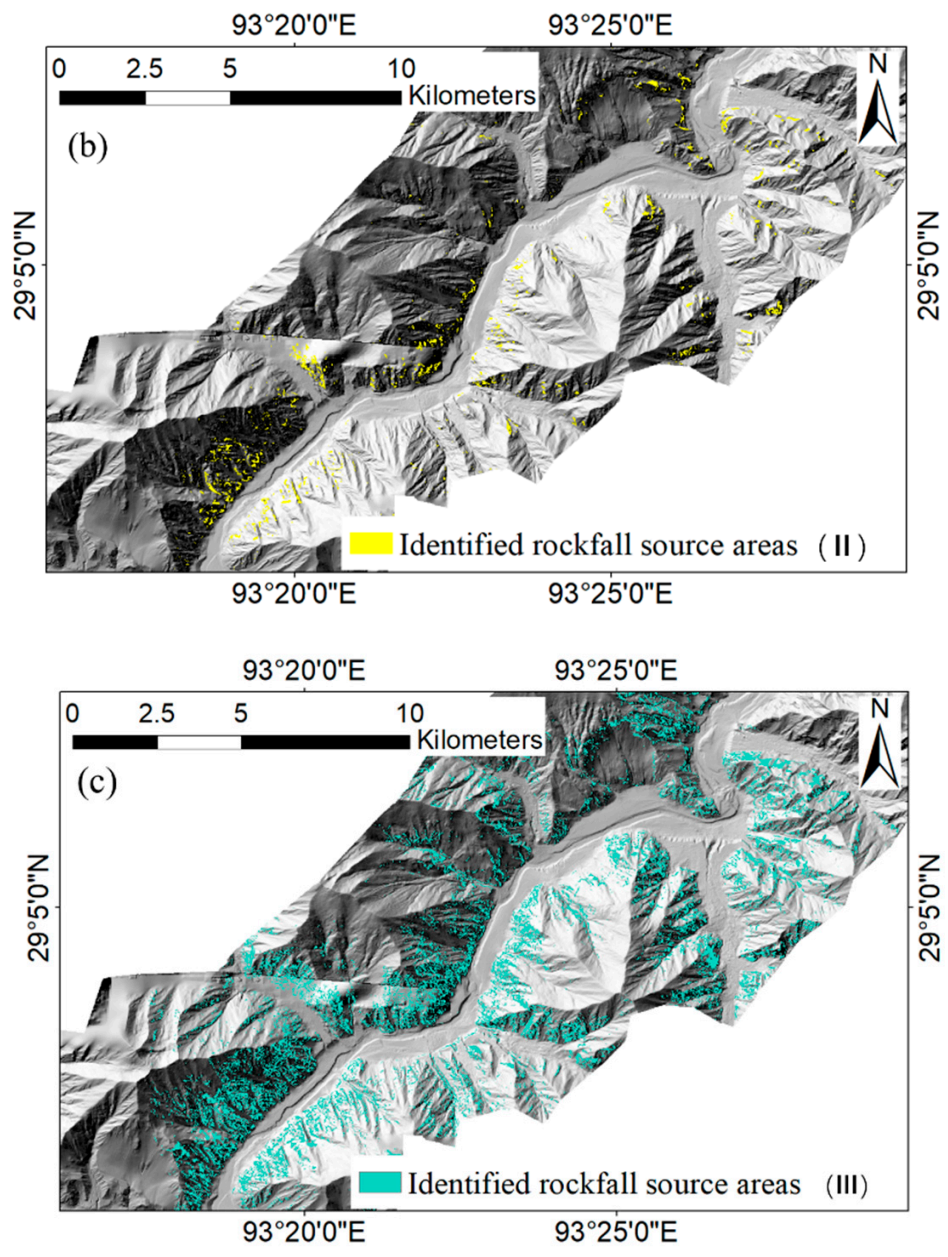

Figure 6. The identification results of the rockfall source areas in the study area. The results of (a-c) correspond to high (I), medium (II) and low (III) rockfall susceptibility classes, respectively.

\subsection{Zoning Map of Rockfall Susceptibility}

In rockfall risk analysis, the rockfall susceptibility assessment is the first step to carry out $[16,28,33]$. The rockfall susceptibility map helps to highlight the spatial distribution of potentially unstable slopes [34], which is usually zoned into different susceptibility classes, e.g., high, medium, and low susceptibility, to represent different rockfall susceptible degrees of slopes. Based on the sketch in Figure 3, if $H>H_{c}$, the area A on the slope is unstable, which means it is prone to rockfall in the future. The larger $\mathrm{H}$ is than $\mathrm{Hc}$, the higher the possibility of rockfall in area $\mathrm{A}$, and hence the higher rockfall susceptibility of area A. To provide a reference for the susceptibility study following the identification of the rockfall source areas by our approach, the rockfall source areas were zoned into three susceptibility classes, high (I), medium (II), and low susceptibility (III) areas, using the upper envelope, the mean envelope, and the lower envelope in Figure 5. In this way, the regional rockfall susceptibility maps were produced in the study area (Figure 6).

The slope angle and the elevation of all the susceptibility classes were analyzed, and their frequency distributions were obtained. According to the results (Figure 7), the rockfall source areas with different susceptibility classes have different ranges of slope angle. The rockfall source areas within the high susceptibility class are mainly distributed on the slopes with the angles of $60-66^{\circ}$, those of medium susceptibility are distributed on the slopes with the angles of $54-61^{\circ}$, and those of low susceptibility are distributed on the slopes with the angles of $46-55^{\circ}$. However, based on the distribution statistics of elevation in Figure 7, no obvious relationship between elevation and susceptibility classes was observed in this study. 
Susceptibility
class

I

II

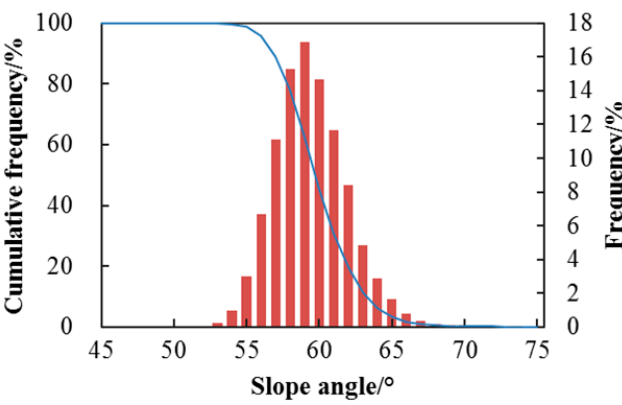

III

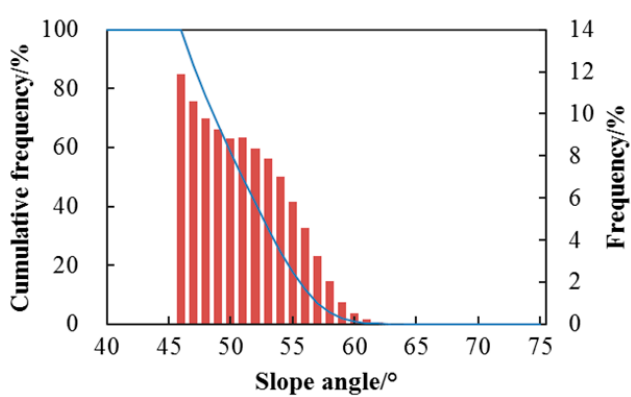

Distribution statistics of elevation $/ \mathrm{m}$
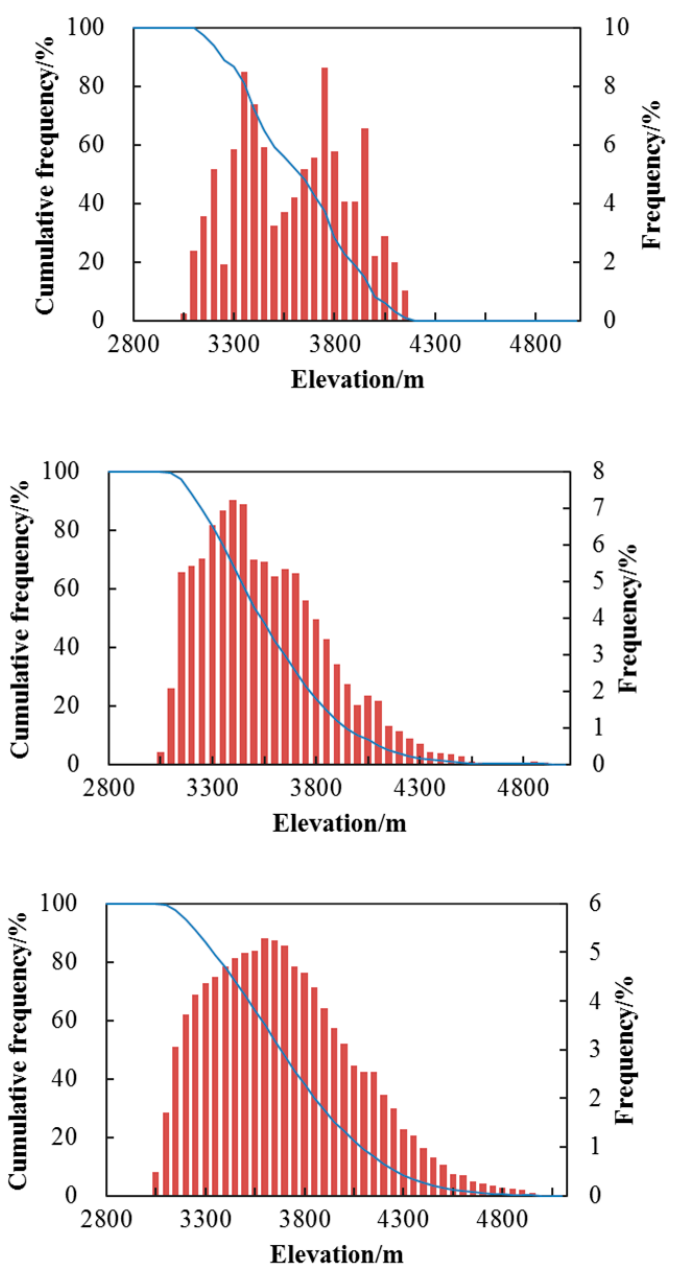

Figure 7. The distribution of slope and elevation of the identified rockfall source areas within different susceptibility classes.

\section{Discussion}

It is important to validate the prediction results in prediction modeling [35]. Hence, the validation of our proposed new approach is discussed here. The uncertainty in our new approach is mainly derived from the process of calculating the rock mass strength parameters, defining the specific area (A) used for searching the rockfall source areas, and the resolution of the DEM.

\subsection{Validation}

Proper validation should be based on the comparison between the prediction results and the actual characteristics affected by future rockfalls $[16,35]$. The selection of approaches depends on the characteristics of dataset. In this study, the space partition to separate our rockfall inventory into two groups was chosen since information was lacking related to the time of the 235 historical rockfalls (Figure 8). To validate the prediction result, the rockfall inventory was partitioned into two groups. One group was used for prediction (Figure 1a) and the other was used for validation (Figure 1b). 


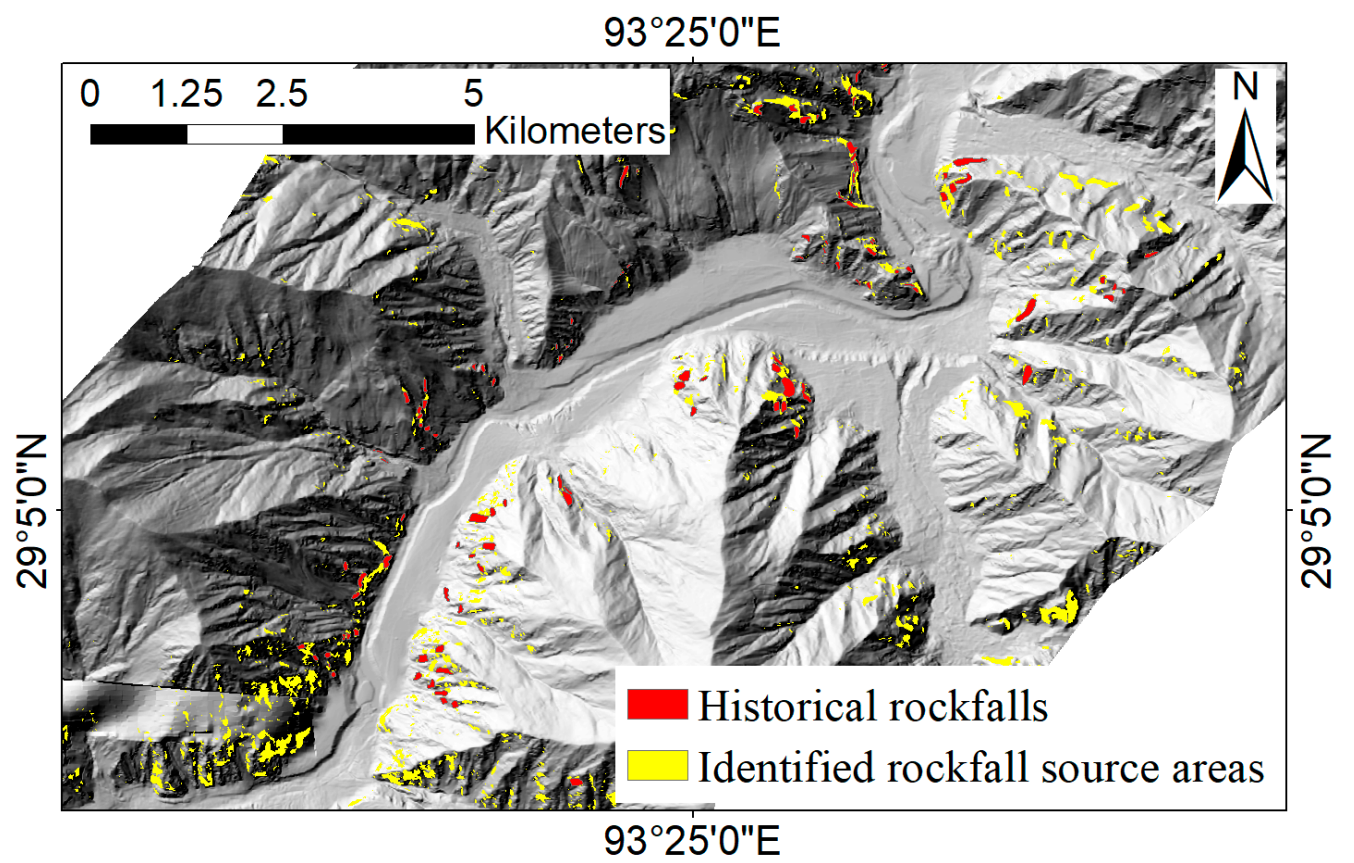

Figure 8. The validation of the prediction result obtained by using one group of historical rockfalls separated by the space partition (Figure 1a).

The first group with 118 historical rockfalls (Figure 1a) was adopted to calculate the rock mass strength and build the R-S relationship curve. According to the fitting result of the selected 118 rockfall sources, the minimum and maximum rock mass cohesions $(c)$ are 28 and $230 \mathrm{kPa}$, respectively, and both internal friction angles $(\varphi)$ are $22^{\circ}$. To present a common case of application, we used the mean value of the upper envelope and the lower envelope to build the R-S relationship curve in this paper. Based on the procedure of our approach (Figure 3), the rockfall source areas were obtained. The second group with 117 historical rockfalls (Figure 1b) was used to validate the prediction result (Figure 8). The validation result demonstrated that 117 historical rockfalls occupy $71.92 \%$ of the rockfall source areas in the validation area predicted by our new approach, which proves to be a good prediction.

Besides, the prediction result was validated with field work. Most of the rockfall source areas identified by our approach are distributed on slopes with high relief and steep terrain. This is consistent with the observation of rockfall distribution on the maps of DEM and hillshade (Figure 8). Most of the historical rockfall deposits are distributed at the foot of the slopes with identified rockfall source areas, proving that the identified rockfall source areas are distributed rockfalls that occurred in the past, and that unstable slopes are prone to rockfall in the future [19].

\subsection{Uncertainty Analysis}

An accurate calculation of rock mass strength parameters is the fundamental work in our new proposed approach. For example, for a slope with a specific relief $(\mathrm{H})$ and slope angle $(\beta)$, the bigger the rock mass strength estimated, the higher the value of the limit relief (Hc) calculated by Equation (1), and hence the bigger the difference between Hc and H. For the stability of the slope, more stable (i.e., the lower rockfall susceptibility) slopes were predicted. In other words, if the rock mass strength parameters are overestimated, the slope would be prone to rockfall with an incorrect prediction of low susceptibility. In our new approach, the more accurate estimated rock mass strength parameters will greatly improve the accuracy of the $\mathrm{R}-\mathrm{S}$ relationship curve, and hence the prediction results of rockfall source areas. However, it is very difficult to quantitatively estimate the rock mass strength at the landscape. An in situ test is recognized as one of the most reliable 
methods to obtain rock mass strength $[10,20]$, which proves to be very difficult to carry out in high mountain areas. In this paper, the back analysis for rock mass strength using historical rockfalls based on the Culmann model is adopted, whose accuracy depends on the reliability of the identification, the boundary of historical rockfalls, and the uncertainty in fitting the data.

According to the procedure of our approach and the sketch in Figure 3, the specific area (A) is also important in affecting the accuracy of the prediction result. For example, if a smaller area than the real one was defined to search the potential rockfall source areas, a lower relief $(\mathrm{H})$ than the real value of a potential source area would be obtained. For the same slope angle and corresponding estimated Hc, the area would mistakenly be regarded as more stable (Figure 3 ) than its real stability state. In this paper, the mean area of historical rockfalls is defined as the specific area (A) for searching the potential rockfall source areas. The definition of the parameter could be further studied in the future.

The resolution of DEM plays an important role in controlling the accuracy of the result [5] because it is the basic data in almost every data process of our new approach. The higher the resolution of the DEM, the higher the accuracy of the values of the relief and slope angles of historical rockfalls and the potential rockfall source areas. However, it is not easy to acquire a high-quality DEM in a large study area currently.

\section{Conclusions}

The main type of rock mass failure in the Wolong area of Tibet is rockfall. Using data from helicopter-based remote sensing imagery, a DEM with $10 \mathrm{~m}$ resolution of the study area, images from Google Earth, and field work, a rockfall inventory including 235 rockfalls scars on bedrocks and 109 rockfall deposits was prepared. According to the statistical results, the relief of historical rockfalls is mainly distributed between 40 and $130 \mathrm{~m}$, the slope angle is generally larger than $45^{\circ}$, and the area of each historical rockfall scar is generally less than $9000 \mathrm{~m}^{2}$. A clear inverse relationship between the relief and slope angles of historical rockfalls enabled us to calculate the rock mass strength at the landscape scale base on the Culmann model, obtaining the minimum and maximum rock mass cohesions (c) in the study area from 28 to $270 \mathrm{kPa}$, respectively, and the internal friction angle of $23^{\circ}$.

Required by the actual needs of identification on high and steep slopes, this paper proposes a new approach using the relief-slope angle relationship to identify the rockfall source areas controlled by the rock mass strength on a regional scale. Based on historical rockfalls and a high-resolution DEM, we obtained the parameters used in our proposed approach. By applying our approach, the potential rockfall source areas in the study area were identified and further zoned into three susceptibility classes that could be used as a reference for the study of regional rockfall susceptibility assessment. According to the results, rockfall source areas within the high susceptibility class are mainly distributed on the slopes with the angles of $60-66^{\circ}$, those of medium susceptibility are distributed on the slopes with the angles of $54-61^{\circ}$, and those of low susceptibility are distributed on the slopes with the angles of $46-55^{\circ}$.

By the space partition and the field work, our prediction result was validated. Most of the rockfall source areas (i.e., $71.92 \%$ ) identified in the validation area are occupied by actual historical rockfalls, which proves the accurate prediction ability of our approach. The locations of the rockfall source areas obtained in this paper could provide reference for actual rockfall disaster prevention and mitigation in the study area. Our proposed approach could be used to identify the rockfall source areas in the regional areas that are not accessible. In the paper, the dominant uncertainty is derived from the process of calculating the rock mass strength parameters, the process of defining the specific area (A) that is used for searching the rockfall source areas, and the resolution of the DEM. Many more studies estimating the rock mass strength at the landscape scale and defining the specific area (A) are necessary in the future. 
Author Contributions: Conceptualization, X.W.; methodology X.W., H.L.; formal analysis, H.L., J.S.; writing-original draft preparation, X.W., H.L.; writing-review and editing, X.W.; visualization, H.L.; supervision, X.W.; project administration, J.S.; funding acquisition, X.W. All authors have read and agreed to the published version of the manuscript.

Funding: This work was supported by the Second Tibetan Plateau Scientific Expedition and Research Program (STEP) (Grant No. 2019QZKK0904), the Strategic Priority Research Program of the Chinese Academy of Sciences (Grant No. XDA23090402), the Application of Synthetic Aperture RadarBased Geological Hazard Analysis Technology on the Strategic Electricity Transmission Passage of Sichuan-Tibet Plateau (Grant No. 52199918000C).

Acknowledgments: We thank the program research group of the State Grid Corporation of China for providing the $10 \mathrm{~m}$ resolution topographic DEM data.

Conflicts of Interest: The authors declare no conflict of interest. The funders had no role in the design of the study; in the collection, analyses, or interpretation of data; in the writing of the manuscript; or in the decision to publish the results.

\section{References}

1. Mazzoccola, D.F.; Hudson, J.A. A comprehensive method of rock mass characterization for indicating natural slope instability. $Q$. J. Eng. Geol. Hydrogeol. 1996, 29, 37-56. [CrossRef]

2. Bunce, C.M.; Cruden, D.M.; Morgenstern, N.R. Assessment of the hazard from rock fall on a highway. Can. Geotech. J. 1997, 34, 344-356. [CrossRef]

3. Guzzetti, F.; Carrara, A.; Cardinali, M.; Reichenbach, P. Landslide hazard evaluation: A review of current techniques and their application in a multi-scale study, Central Italy. Geomorphology 1999, 31, 181-216. [CrossRef]

4. Gokceoglu, C.; Sonmez, H.; Ercanoglu, M. Discontinuity controlled probabilistic slope failure risk maps of the Altindag (settlement) region in Turkey. Eng. Geol. 2000, 55, 277-296. [CrossRef]

5. Loye, A.; Jaboyedoff, M.; Pedrazzini, A. Identification of potential rockfall source areas at a regional scale using a DEM-based geomorphometric analysis. Nat. Hazards Earth Syst. Sci. 2009, 9, 1643-1653. [CrossRef]

6. Liu, H.; Wang, X.; Liao, X.; Sun, J.; Zhang, S. Rockfall Investigation and Hazard Assessment from Nang County to Jiacha County in Tibet. Appl. Sci. 2019, 10, 247. [CrossRef]

7. Wang, X.; Frattini, P.; Stead, D.; Sun, J.; Liu, H.; Valagussa, A.; Li, L. Dynamic rockfall risk analysis. Eng. Geol. 2020, $272,105622$. [CrossRef]

8. Wang, X.; Zhang, L.; Wang, S.; Agliardi, F.; Frattini, P.; Crosta, G.B.; Yang, Z. Field investigation and rockfall hazard zonation at the Shijing Mountains Sutra caves cultural heritage (China). Environ. Earth Sci. 2011, 66, 1897-1908. [CrossRef]

9. Stead, D.; Wolter, A. A critical review of rock slope failure mechanisms: The importance of structural geology. J. Struct. Geol. 2015, 74, 1-23. [CrossRef]

10. Saroglou, C.; Qi, S.; Guo, S.; Wu, F. ARMR, a new classification system for the rating of anisotropic rock masses. Bull. Int. Assoc. Eng. Geol. 2019, 78, 3611-3626. [CrossRef]

11. Jaboyedoff, M.; Metzger, R.; Oppikofer, T.; Couture, R.; Derron, M.H.; Locat, J.; Turmel, D. New insight techniques to analyze rock-slope relief using DEM and 3D-imaging cloud points: COLTOP 3D software. In Proceedings of the 1st Canada-US Rock mechanics Symposium, Vancouver, BC, Canada, 27-31 May 2007; pp. 27-31. [CrossRef]

12. DiMatteo, L.; Romeo, S.; Kieffer, D.S. Rockfall analysis in Alpine area by using a reliable integrated monitoring system: Results from the Ingelsberg slope (Salzburg Land, Austria). Bull. Eng. Geol. Environ. 2017, 76, 413-420. [CrossRef]

13. Mazzanti, P.; Schilirò, L.; Martino, S.; Antonielli, B.; Brizi, E.; Brunetti, A.; Margottini, C.; Mugnozza, G.S. The Contribution of Terrestrial Laser Scanning to the Analysis of Cliff Slope Stability in Sugano (Central Italy). Remote Sens. 2018, 10, 1475. [CrossRef]

14. Kovanič, L'.; Blistan, P.; Urban, R.; Štroner, M.; Blišt'anová, M.; Bartoš, K.; Pukanská, K. Analysis of the Suitability of HighResolution DEM Obtained Using ALS and UAS (SfM) for the Identification of Changes and Monitoring the Development of Selected Geohazards in the Alpine Environment-A Case Study in High Tatras, Slovakia. Remote Sens. 2020, 12, 3901. [CrossRef]

15. Cascini, L. Applicability of landslide susceptibility and hazard zoning at different scales. Eng. Geol. 2008, 102, 164-177. [CrossRef]

16. Wang, X.L.; Zhang, L.Q.; Wang, S.J.; Lari, S. Regional landslide susceptibility zoning with considering the aggregation of landslide points and the weights of factors. Landslides 2014, 11, 399-409. [CrossRef]

17. Budetta, P.; De Luca, C.; Nappi, M. Quantitative rockfall risk assessment for an important road by means of the rockfall risk management (RO.MA.) method. Bull. Int. Assoc. Eng. Geol. 2016, 75, 1377-1397. [CrossRef]

18. Duarte, R.M.; Marquínez, J. The influence of environmental and lithologic factors on rockfall at a regional scale: An evaluation using GIS. Geomorphology 2002, 43, 117-136. [CrossRef]

19. Frattini, P.; Crosta, G.; Carrara, A.; Agliardi, F. Assessment of rockfall susceptibility by integrating statistical and physically-based approaches. Geomorphology 2008, 94, 419-437. [CrossRef]

20. Hoek, E. Strength of jointed rock masses. Géotechnique 1983, 33, 187-223. [CrossRef]

21. Gudmundsson, A. Rock Fractures in Geological Processes; Cambridge University Press (CUP): Cambridge, UK, 2011. 
22. Francioni, M.; Antonaci, F.; Sciarra, N.; Robiati, C.; Coggan, J.; Stead, D.; Calamita, F. Application of Unmanned Aerial Vehicle Data and Discrete Fracture Network Models for Improved Rockfall Simulations. Remote Sens. 2020, 12, 2053. [CrossRef]

23. Culmann, C. Die Graphische Statik; Meyer and Zeller: Zurich, Switzerland, 1875; 644p.

24. Schmidt, K.M.; Montgomery, D.R. Limits to Relief. Science 1995, 270, 617-620. [CrossRef]

25. Montgomery, D.R.; Brandon, M.T. Topographic controls on erosion rates in tectonically active mountain ranges. Earth Planet. Sci. Lett. 2002, 201, 481-489. [CrossRef]

26. Crosta, G.B.; Utili, S.; De Blasio, F.V.; Castellanza, R. Reassessing rock mass properties and slope instability triggering conditions in Valles Marineris, Mars. Earth Planet. Sci. Lett. 2014, 388, 329-342. [CrossRef]

27. DiBiase, R.A.; Rossi, M.W.; Neely, A.B. Fracture density and grain size controls on the relief structure of bedrock landscapes. Geology 2018, 46, 399-402. [CrossRef]

28. Crosta, G.B.; Agliardi, F. A methodology for physically based rockfall hazard assessment. Nat. Hazards Earth Syst. Sci. 2003, 3, 407-422. [CrossRef]

29. Quidelleur, X.; Grove, M.; Lovera, O.M.; Harrison, T.M.; Yin, A.; Ryerson, F.J. Thermal evolution and slip history of the Renbu Zedong Thrust, southeastern Tibet. J. Geophys. Res. Space Phys. 1997, 102, 2659-2679. [CrossRef]

30. Xu, Z.-Q.; Dilek, Y.; Yang, J.-S.; Liang, F.-H.; Liu, F.; Ba, D.-Z.; Cai, Z.-H.; Li, G.-W.; Dong, H.-W.; Ji, S.-C. Crustal structure of the Indus-Tsangpo suture zone and its ophiolites in southern Tibet. Gondwana Res. 2015, 27, 507-524. [CrossRef]

31. Burbank, D.W.; Leland, J.; Fielding, E.; Anderson, R.S.; Brozovic, N.; Reid, M.R.; Duncan, C. Bedrock incision, rock uplift and threshold hillslopes in the northwestern Himalayas. Nat. Cell Biol. 1996, 379, 505-510. [CrossRef]

32. Finnegan, N.J.; Hallet, B.; Montgomery, D.R.; Zeitler, P.K.; Stone, J.O.; Anders, A.M.; Liu, Y.P. Coupling of rock uplift and river incision in the Namche Barwa-Gyala Peri massif, Tibet. Geol. Soc. Am. Bull. 2008, 120, 142-155. [CrossRef]

33. Fell, R.; Cororninas, J.; Bonnard, C.; Cascini, L.; Leroi, E.; Savage, W.Z. Guidelines for landslide susceptibility, hazard and risk-zoning for land use planning. Eng. Geol. 2008, 102, 85-98. [CrossRef]

34. Ayalew, L.; Yamagishi, H.; Maruib, H.; Kannoc, T. Landslides in Sado Island of Japan: Part II. GIS-based susceptibility mapping with comparisons of results from two methods and verifications. Eng. Geol. 2005, 81, 432-445. [CrossRef]

35. Chung, C.F.; Fabbri, A.G. Validation of spatial prediction models for landslide hazard mapping. Nat. Hazard. $2003,30,451-472$. [CrossRef] 